\section{EL DEPARTAMENTO \\ DE MADERAS DEL INSTITUTO NACIONAL DE \\ INVESTIGACIONES AGRARIAS}

\author{
Alejandro López de Roma \\ Dr. Ingeniero de Montes, \\ Jefe del Dpto. de Maderas. INIA \\ $071-16$
}

La madera, uno de los materiales más utilizados por el hombre en todos los tiempos, ha sido posiblemente el que más ha tardado en conocerse física y tecnológicamente. Después de una utilización sentimental y empírica, se empezó realmente a estudiar a principios de nuestro siglo, cuando se convierte en materia prima fundamental en la construcción de aviones. A partir de este momento es cuando se empieza a conocer su estructura y reología, sus propiedades mecánicas y físicas y, en consecuencia, a desarrollarse toda una tecnología que intenta aprovechar al máximo sus posibilidades.

El estudio de la madera y de sus productos derivados, así como el de su mejor aprovechamiento industrial, se ha realizado en España hasta el momento, prácticamente en exclusiva, por el Departamento de Maderas del Instituto Nacional de Investigaciones Agrarias, Organismo Autónomo del Ministerio de

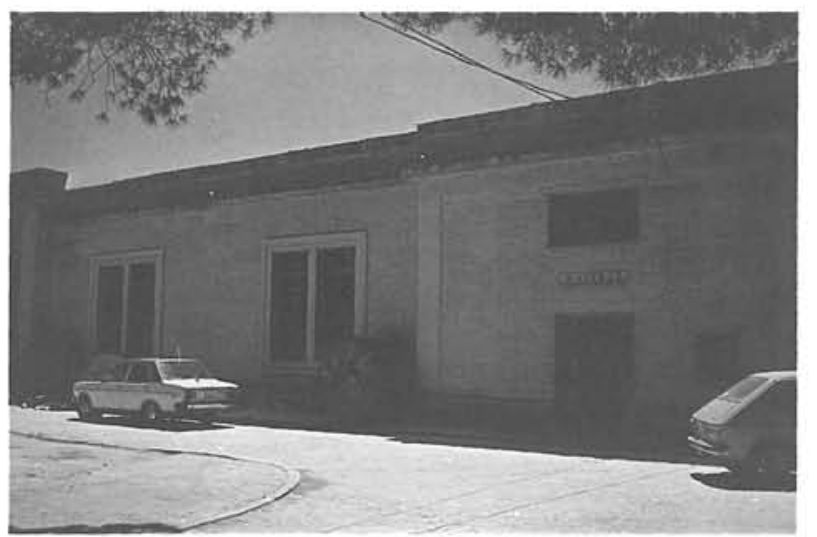

Agricultura, Pesca y Alimentación. Esta adscripción administrativa, cobra todo su sentido, si se comprende la íntima relación existente entre el monte, la producción de madera y su

transformación industrial, ya que no puede decirse que la madera cuente con una específica utilidad social si no existe una industria que la transforme $\mathrm{y}$, a la inversa, no puede existir esta última sin la materia prima que la sustente, sobre todo si se tiene en cuenta que en la actualidad no hay realmente un mercado internacional de madera en rollo.

El Departamento de Maderas, además de apoyar la política que en cada momento determina para el sector el M. de A. P. y A., ha venido centrando sus actividades fundamentalmente en:

- Investigar las propiedades físicas y mecánicas de las diferentes especies de madera, así como de sus productos derivados.

- Desarrollar métodos de ensayo apropiados que permitan determinar las propiedades y características de los nuevos productos y de las estructuras realizadas con ellos, así como su idoneidad a cada tipo de aplicación.

- Investigar y adaptar a las específicas condiciones de la industria española los nuevos procesos tecnológicos.

- Investigar los tratamientos físicos que permitan modificar el comportamiento tecnológico de la madera, así como los sistemas de protección más eficaces contra los agentes bióticos y abióticos.

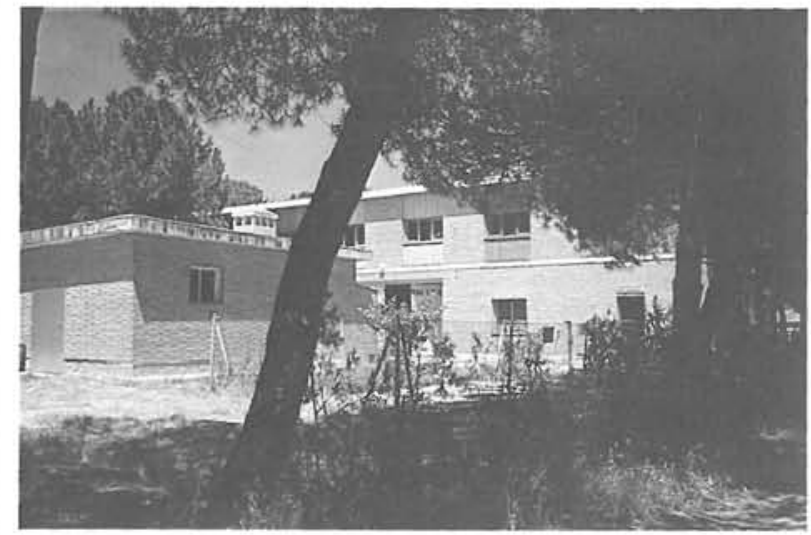




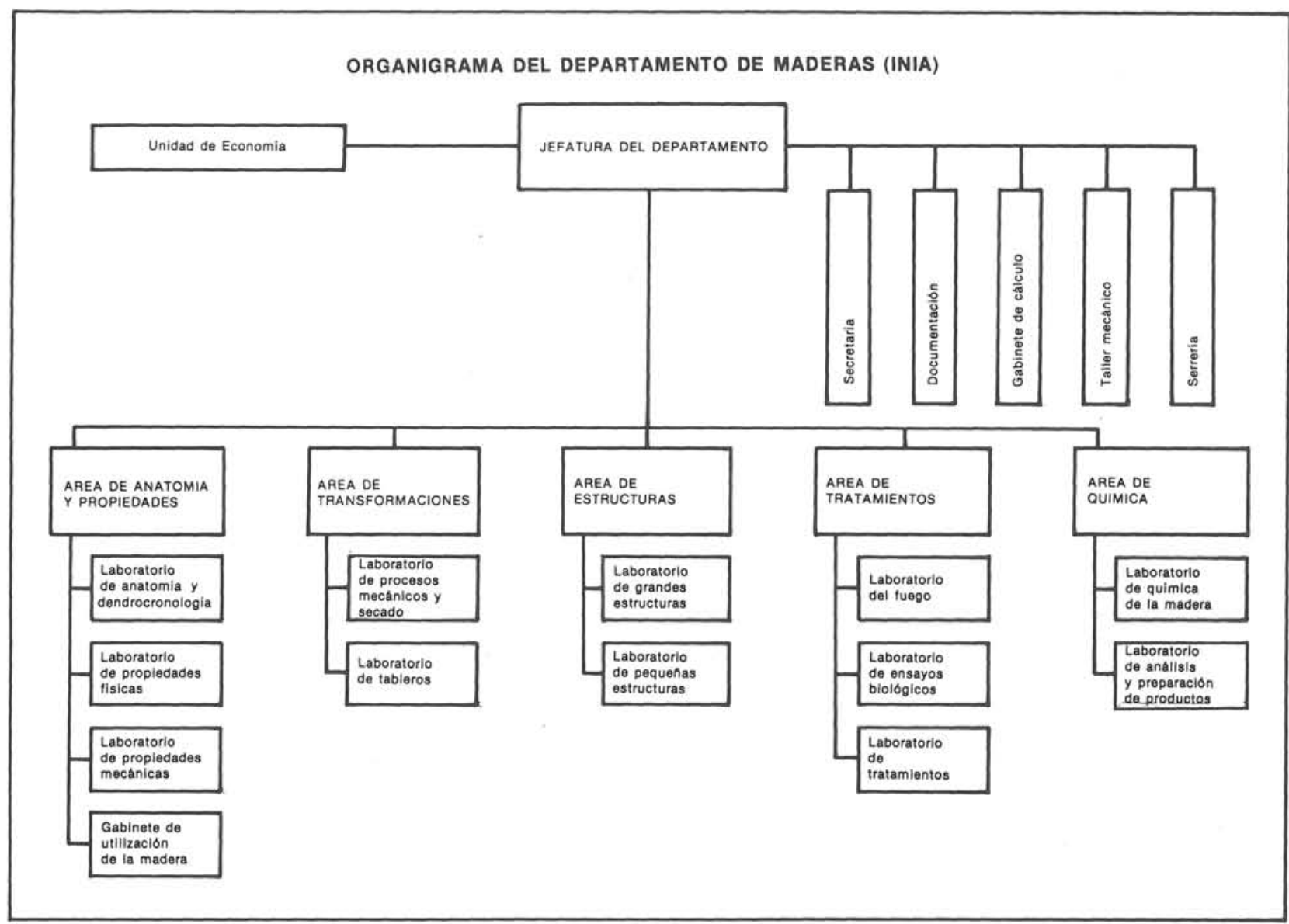

- Transferir tecnología a las diferentes empresas industriales del sector, que en número superior a las 40.000 , dan ocupación aproximadamente a 300.000 trabajadores.

- Normalizar la madera, productos derivados y estructuras formadas con ellos y realizar los ensayos de homologación como premisa indispensable en una política eficaz de defensa del consumidor.

Para ello, cuenta con la estructura que se recoge en el Organigrama adjunto, en la que los diferentes Laboratorios, con una dotación desigual en medios humanos y materiales, realizan de forma sintetizada las siguientes actividades.

\section{Unidad de economía}

Estando definido el sector de la madera por todas aquellas actividades mercantiles e industriales en las que la madera constituye la materia prima básica, esta Unidad, en la actualidad en constitución, tendrá como misiones fundamentales el análisis de:

- La oferta de materia prima.

- La estructura industrial.

- La estructura del mercado.

- La demanda de productos finales.
Todo ello, con objeto de determinar el conjunto de parámetros que permitan establecer orientaciones estructurales que faciliten su desarrollo armónico.

\section{AREA DE ANATOMIA Y PROPIEDADES}

Tiene como objetivo principal el conocimiento de la estructura anatómica y de las propiedades físicas y mecánicas de las diferentes especies de madera, prestando especial atención a las autóctonas, a fin de determinar su aptitud a las diferentes utilizaciones posibles.

\section{Laboratorio de Anatomía y Dendrocronología}

Se dedica principalmente a la identificación de especies y al estudio y datación de maderas

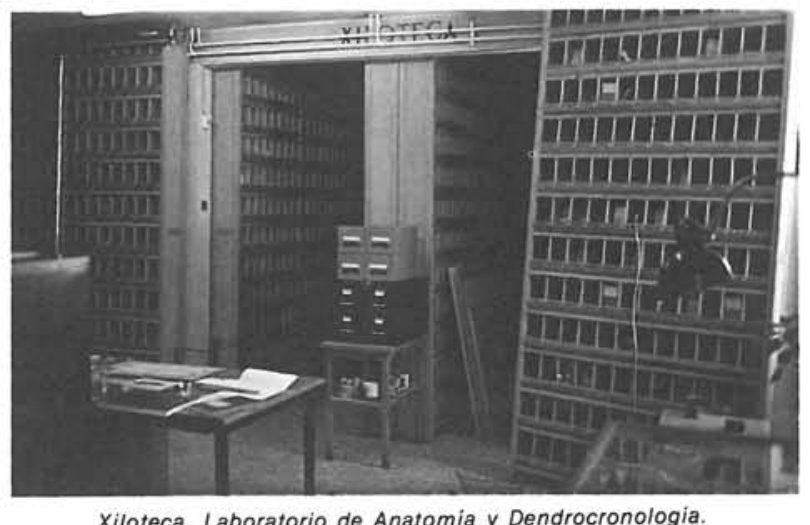




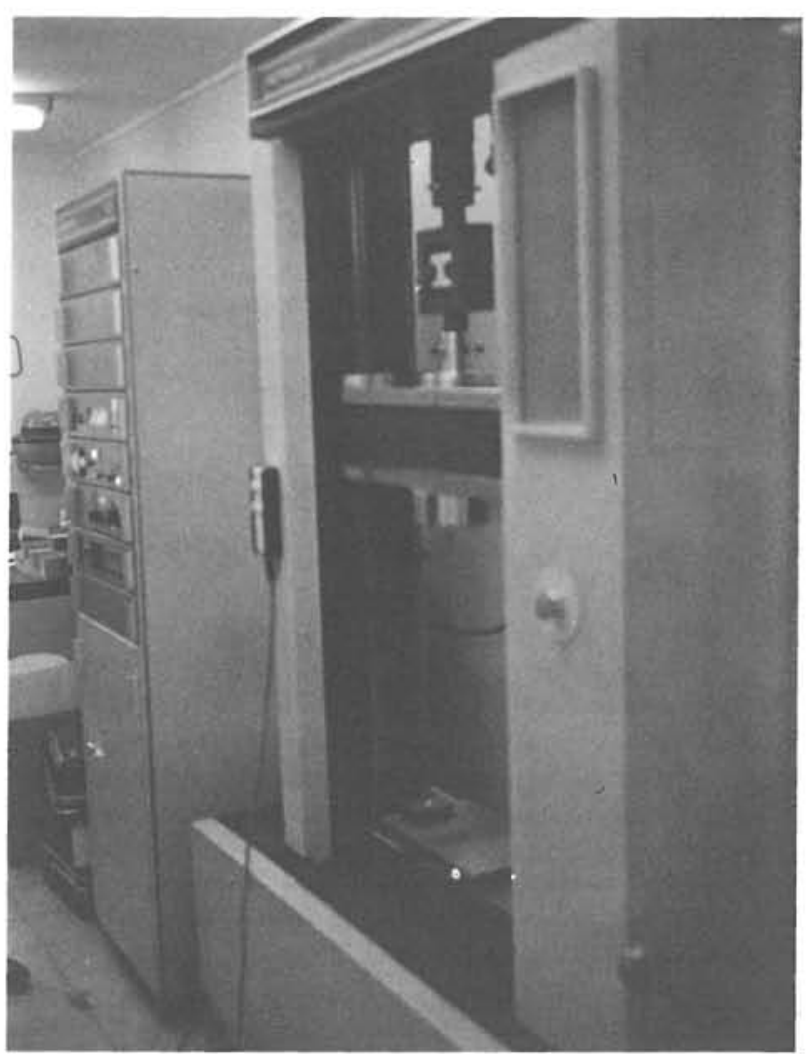

Máquina universal de ensayos mecánicos. Laboratorio de Propiedades Mecánicas.

antiguas, para lo que dispone de:

- Xiloteca con 8.000 maderas diferentes.

- Banco de datos dendrocronológicos. (En constitución).

\section{Laboratorio de Propiedades Físicas}

Determina en la madera y productos derivados:

- Humedad e hinchazón y merma.

- Peso específico.

- Propiedades eléctricas, térmicas y acústicas.

- Dureza, etc.

\section{Laboratorio de Propiedades Mecánicas}

Determina en la madera y productos derivados:

- Resistencia a la tracción, compresión, flexión, cortadura, etc.

- Tensiones básicas.

— Módulos de elasticidad.

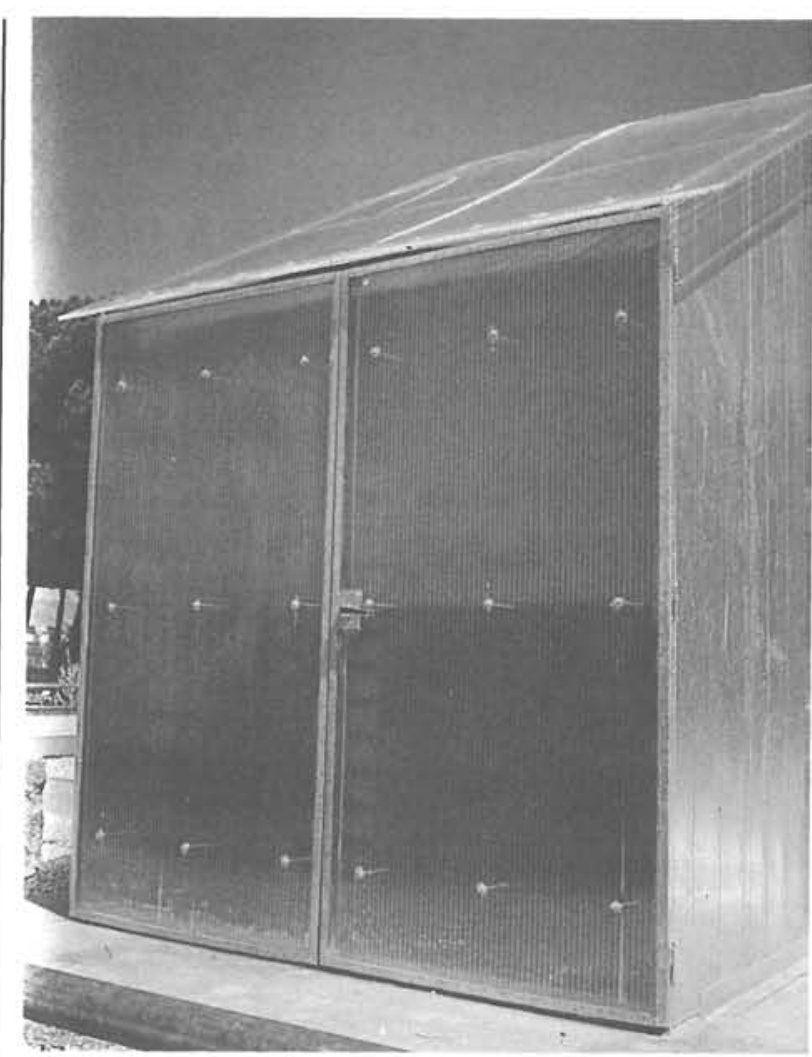

Secadero solar para madera aserrada. Laboratorio de Procesos Mecánicos y Secado.

\section{Gabinete de Utilización de la Madera}

Recopila la información del resto de Laboratorios del Departamento y confecciona las fichas tecnológicas de las diferentes especies de madera.

\section{AREA DE TRANSFORMACIONES}

Tiene como objetivo investigar sobre los fundamentos de los procesos industriales de transformación mecánica de la madera y de sus productos derivados.

\section{Laboratorio de Procesos Mecánicos y Secado}

Estudia los siguientes procesos:

$\star$ Aserrado $\star$ Secado $\star$ Astillado $\star$ Desenrollo.

\section{Laboratorio de Tableros}

Estudia el proceso de fabricación y mejora de las propiedades de:

- Tableros contrachapados.

- Tableros de fibras.

- Tableros de partículas. 


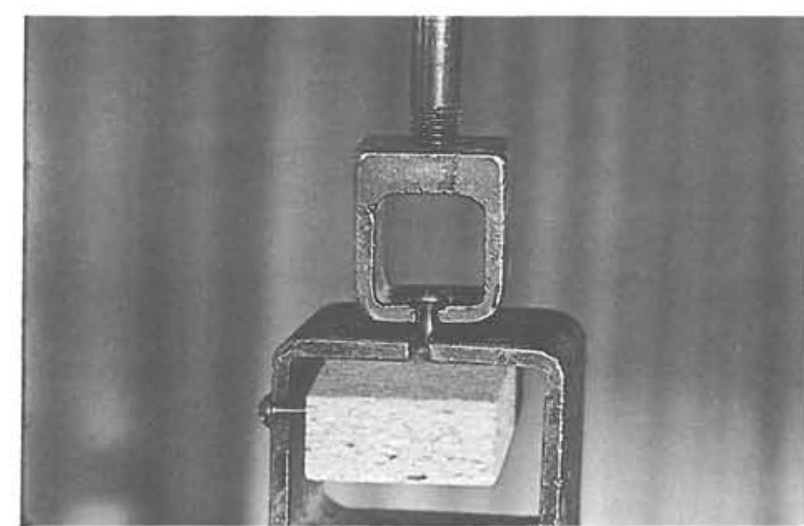

Ensayo de arranque de tornillos. Laboratorio de Tableros.

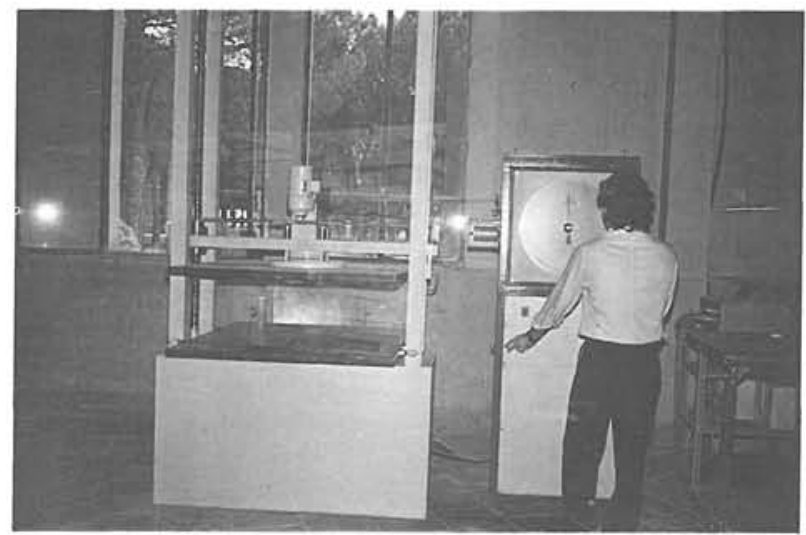

Prensa para ensayos de compresión de embalajes. Laboratorio de Pequenlas Estructuras.

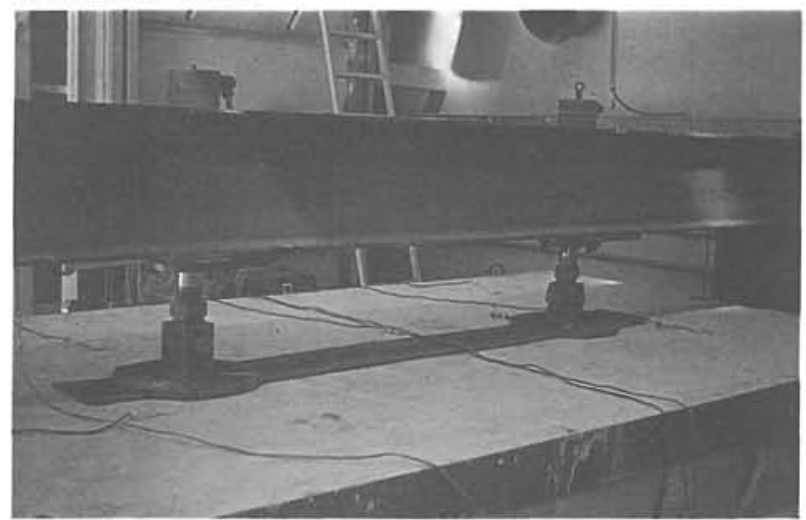

Ensayo de resistencia al fuego de un techo de yeso y vigas de madere. Laboratorio del Fuego.

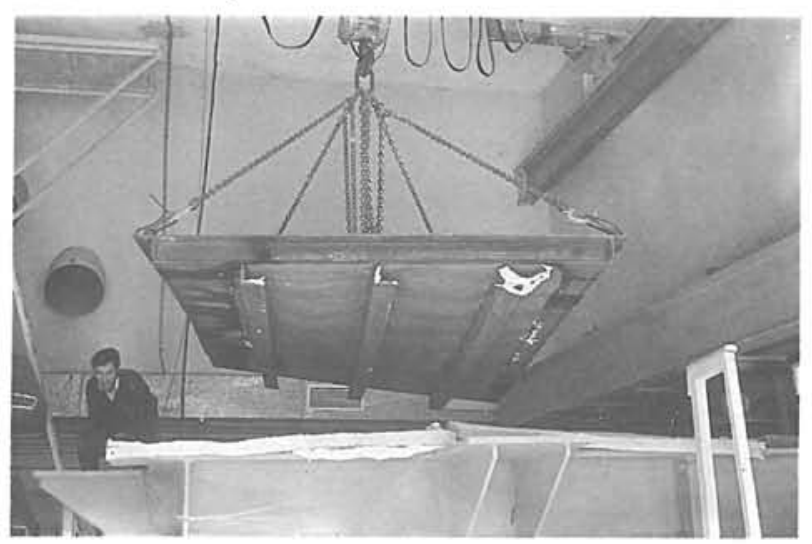

Elemento de una cubierta de buque después del ensayo de resistencie al fuego. Laboratorio del Fuego.

\section{AREA DE ESTRUCTURAS}

Tiene como objetivo el diseño, cálculo, construcción, ensayo y puesta en obra de estructuras de madera.

\section{Laboratorio de Grandes Estructuras}

Este laboratorio, en la actualidad en período de formación, trabaja fundamentalmente en la elaboración de normativa y reglamentaciones sobre:

- Estructuras de madera laminada.

- Viviendas prefabricadas.

\section{Laboratorio de Pequeñas Estructuras}

Se dedica a la investigación, normalización, homologación y control de calidad de:

- Puertas.

- Ventanas.

- Embalajes de madera y cartón.

- Pavimentos, etc.

\section{AREA DE TRATAMIENTOS}

Tiene como objetivo el estudio de los protectores y de las técnicas de aplicación, a fin de lograr la máxima eficacia en la protección de las maderas y productos derivados contra la acción de los agentes destructores bióticos (bacterias, hongos e insectos) y abióticos (fuego, radiación solar, cambios de humedad, etc.).

\section{Laboratorio del Fuego}

Centra sus actividades en:

- Estudiar el comportamiento al fuego de las diferentes especies de madera, tableros y estructuras con ellos construidas.

- Determinar la eficacia de toda clase de ignifugantes (sales, barnices, pinturas y productos intumescentes).

- Realizar ensayos de todo tipo de materiales y estructuras para su homologación por el Ministerio de Obras Públicas y Urbanismo.

- Incendios forestales. Estudios de inflamabilidad y combustibilidad de las diferentes especies vegetales, así como de la eficacia en el monte de productos no fitotóxicos retardadores del fuego. 
- Xiloenergética. Estudio del poder calorífico de los residuos del monte y de las industrias de la madera.

\section{Elaboración de Ensayos Biológicos}

Tiene como misiones principales:

- Realizar los ensayos de homologación de los protectores para su inscripción en el Registro Oficial Central de Productos y Material Fitosanitario.

- Poner a punto métodos de laboratorio para determinar la eficacia de los protectores contra los diferentes agentes destructores.

- Estudiar la eficacia de nuevos principios activos que presenten menor toxicidad para el usuario.

- Estudiar los ciclos biológicos y distribución geográfica de los hongos e insectos xilófagos autóctonos.

\section{Laboratorio de Tratamientos}

Se ocupa de mejorar el comportamiento de la madera y productos derivados, estando dotado de los siguientes sistemas de impregnación:

- Pulverización

- Inmersión

- Inmersión caliente-fría

- Difusión

- Vacío-vacío

- Vacío-presión.

\section{AREA DE QUIMICA}

Tiene como objetivo estudiar los componentes químicos de la madera y los procesos industriales relacionados con ellos, así como todos aquellos productos que de una forma $u$ otra están relacionados con las diferentes tecnologías de la madera.

\section{Laboratorio de Química de la Madera}

En la actualidad centra sus estudios en:

- Combustión.

- Carbonización.

- Influencia de las sustancias extractivas en el encolado y acabado.

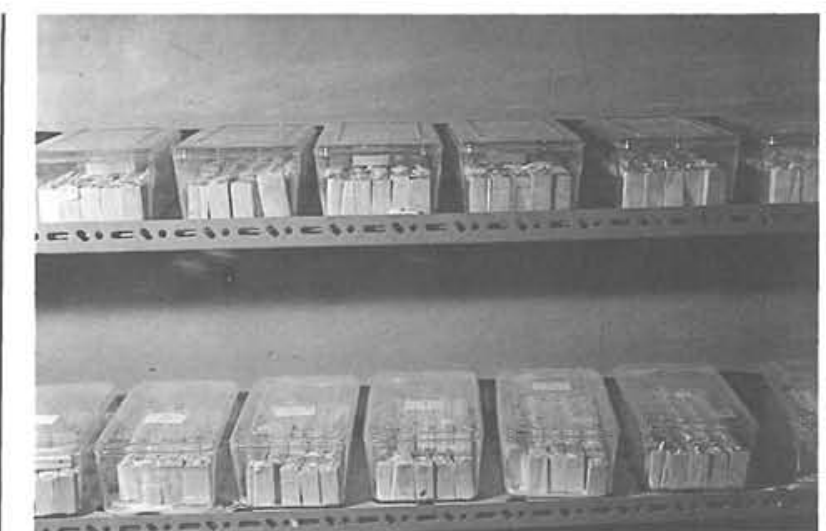

Criadero de Hylotrupes bajulus. L. Laboratorio de Ensayos Biológicos

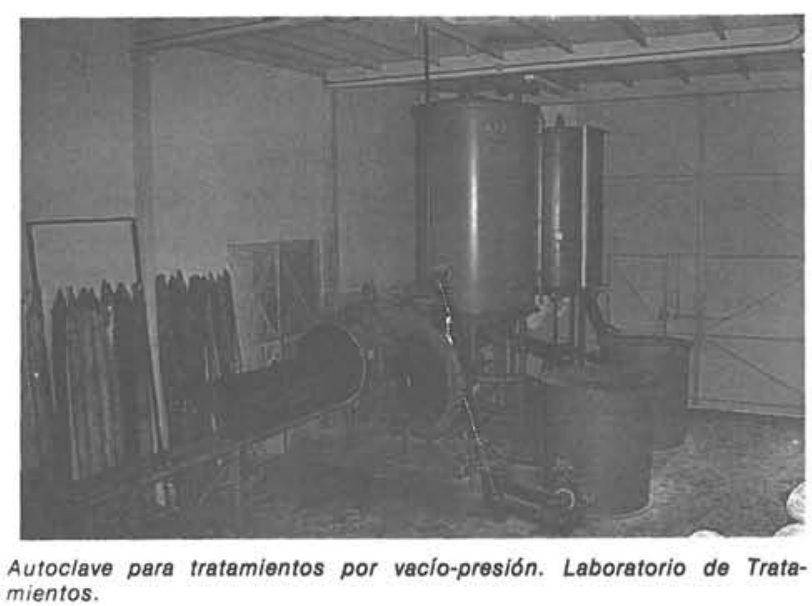

Autoclave
mientos.

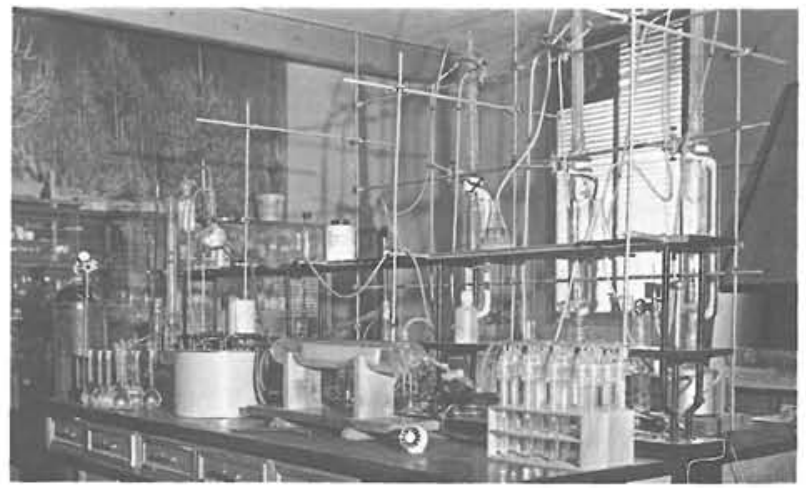

Equipo de arrastre gaseoso de formaldehido. Laboratorio de Quimica de la Madera.

\section{Laboratorio de Análisis y Preparación de} Productos

Realiza análisis cualitativos y cuantitativos, estudia las propiedades e investiga nuevas formulaciones de:

- Colas.

- Barnices.

- Protectores.

- Ignífugos. 


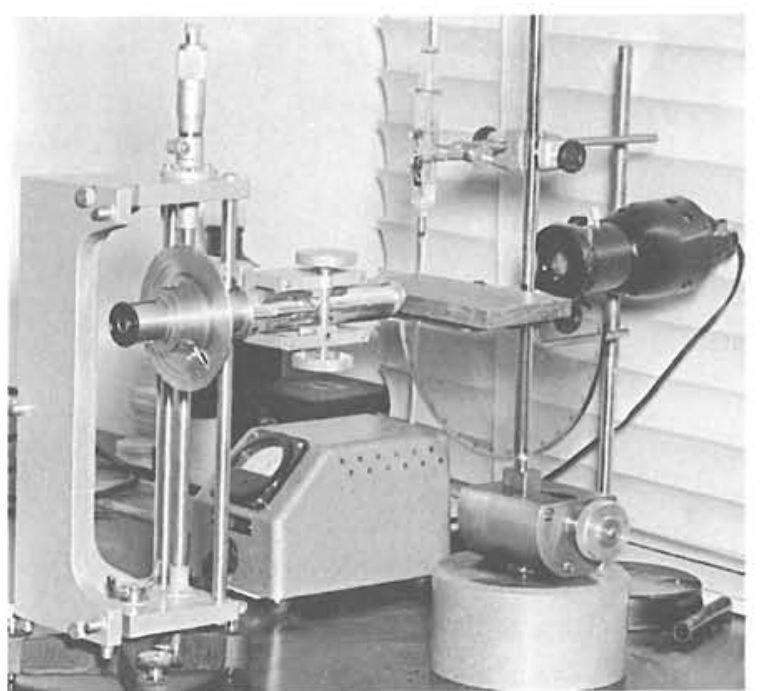

Determinación del espesor de película de un barniz. Laboratorio de Análisis y Preparación de Productos.
El hecho de que en España el uso de la madera como elemento resistente en la construcción sea prácticamente nulo, a pesar de que sus excelentes propiedades y los avances experimentados tanto en su tecnología, como en la de las colas, barnices, protectores, ignífugos, etc., le hayan abierto amplias posibilidades, exige que el Departamento de Maderas realice en los próximos años un esfuerzo notable a fin de promocionar su utilización. En efecto, la construcción de viviendas prefabricadas, la fabricación de estructuras de madera laminada, los complejos plástico-madera y cemento-madera, etc., determina no sólo la necesidad de poner a punto tecnologías que permitan el empleo de las especies de madera autóctonas y una mejor adaptación de los productos finales a nuestros específicos habitos y condiciones climáticas, sino también proceder a las imprescindibles tareas de normalización y control de calidad.

$$
\text { 论拧 }
$$

\section{publicación del IE.T.C.c.}

\section{bases para el diseino solar pasivo}

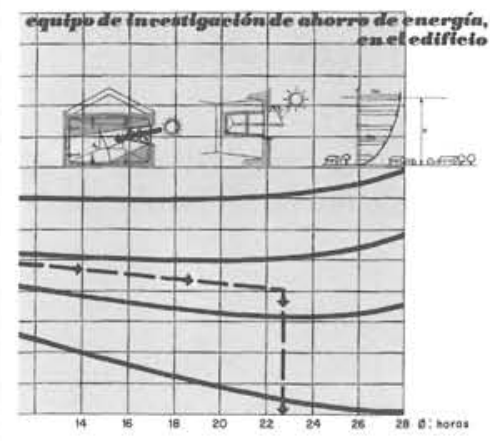

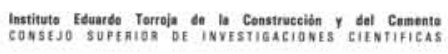

Equipo de Ahorro de Energia en el edificio

Dirección y coordinación: Arturo García Arroyo

M. ${ }^{a}$ José Escorihuela José Luis Esteban José Miguel Frutos Manuel Olaya Bernardo Torroja arquitectónico solar, al margen de las condiciones climáticas y funcionales específicas de cada caso y lugar.

En este libro, utilizando criterios y metodologia pedagógicos, se dan los fundamentos e instrumentos teórico-prácticos necesarios para el planteamiento de todo proyecto arquitectónico solar pasivo, de acuerdo con los principios éticos y económicos de conservación y ahorro de energía. Es decir: respeto de los presupuestos bioclimáticos, búsqueda de la máxima captación y acumulación de la radiación solar, y esmero en el aislamiento térmico de los cerramientos.

Un volumen encuadernado en cartulina ibiza plastificada, a cinco colores, de $16 \times 23 \mathrm{~cm}$, compuesto de 216 páginas, 217 figuras, 87 gráficos, 19 tablas y 10 cuadros.

Madrid, 1983. Precios: España 2.100 ptas.; 30 \$ USA. 